Forthcoming in The Journal of Medicine and Philosophy in a special issue edited by Richard Kim and Dan Haybron.

\title{
Well-being, gamete donation, \& genetic knowledge: the significant interest view ${ }^{1}$ Daniel Groll Carleton College
}

\begin{abstract}
"When I found out, I was not heartbroken or devastated (unlike the popular belief), but I was more curious than anything else. 10 minutes after I found out, a dozen questions flowed out of my mouth in less than a minute."

- A 13-year-old about his experience of learning, during adolescence, that he was donor-conceived (Jadva et al.
\end{abstract} 2009, 1913)

Every year, thousands of children are conceived with gametes from anonymous donors. ${ }^{2}$ By some estimates, there are more than 1 million donor-conceived people living in the United States alone (Ravistky 2012, 18). In all likelihood, they will never know the identity of their donor. ${ }^{3}$ Is this a problem? More specifically, do prospective parents ${ }^{4}$ who plan to conceive a child via gamete donation have a weighty reason to use a known or "identity-release" donor?"

\footnotetext{
${ }^{1}$ Thank you to audiences at the Political Theory Research Group at the University of Edinburgh, the Centre for Ethics, Law and Public Affairs at Warwick University, participants in a workshop on some of this work at Nuffield College, Oxford (and especially Tim Fowler, Halvard Lillehammer, Anna Smajdor, and Liam Shields for delivering comments and Jonathan Parry and Jessica Begon for organizing it), Kieran Oberman, Kim Brownlee, Alice MacLachlan, Guy Fletcher, Richard Kim, Dan Haybron, Emily Carroll, Dorothy MacKinnon, Rivka Weinberg, John Appleby, Kalle Grill, Anca Gheaus, Emily Tilton and an anonymous referee from this journal for valuable comments and discussion.

${ }^{2}$ The United States, Canada, France, Denmark, Belgium, and Spain all allow for anonymous gamete donation. In all of these countries except France conceiving with gametes from a known, or "identity-release" donor, is permitted. In Washington State, identity-release donation is the default unless the donor specifically opts out.

${ }^{3}$ Although this might be changing. See Kramer 2016.

${ }^{4}$ I intend here a normative sense of "parent" according to which a parent is someone who incurs the obligation to raise the child. This notion of parent is conceptually distinct from merely descriptive senses of the term as they figure in concepts like "biological parent" or "genetic parent".

${ }^{5}$ There are three kinds of gamete donation: sperm donation, egg donation, and embryo donation (also known as "double donation"). I do not differentiate between these in what follows, although my focus is largely on sperm donation.
} 
The simplest reason to think the answer is "yes" appeals to the idea that having knowledge of one's genetic parents - or simply "genetic knowledge" as I'll call it - can be critically important for medical reasons (Ravitsky 2012). However, stopping with the Medical Reasons view short-circuits exploration of the more interesting question of whether there are other, perhaps more significant, reasons for people to use a known donor. So, my question is this: if there were no medical reasons to have access to genetic knowledge, would there still be reason(s) for prospective parents to use a known donor? The answer, I will argue, is "yes".

Some who answer "yes," claim that having genetic knowledge is (nearly) always profoundly important for a person's flourishing apart from the potential medical benefits. ${ }^{6}$ Others think that people have a right to genetic knowledge, either basically or because they have a general autonomy right to determine their own identity. ${ }^{7}$

My view doesn't depend on either the idea that genetic knowledge is profoundly prudentially important or that donor-conceived people have a right to genetic knowledge. Rather it turns on general claims about 1) parents' obligations to help promote their children's well-being and 2) the connection between a person's well-being and the satisfaction of what I will call their "worthwhile significant subjective interests." To put my view (too) simply: the fact that a donorconceived person - who knows she is donor-conceived ${ }^{8}$ - is likely to be very interested in acquiring genetic knowledge gives prospective parents a weighty reason to use an identityrelease donor. This is because parents should promote their children's well-being through the satisfaction of their children's worthwhile significant interests.

I want to foreground a central feature of the Significant Interest view: it does not directly depend on claims about the value of genetic knowledge. Most of the normative work in the argument is done by the premise that it matters that many donor-conceived people are subjectively interested in acquiring genetic knowledge. In other words, the Significant Interest view turns on a claim about the importance of the psychology of many donor-conceived people.

Admittedly, it does not turn only on that claim. I am committed to the idea that we should (normally) see a donor-conceived person's subjective interest in acquiring genetic knowledge as

\footnotetext{
${ }^{6}$ See, for example, Velleman 2005 \& 2008 and maybe JL Nelson 1992. I say more about Velleman's views in just a bit.

${ }^{7}$ This claim is argued for explicitly in Ravitsky 2014 and appealed to in Pratten 2012. See Lucy Frith 2001a and $2001 \mathrm{~b}$ for discussion of how talk about the "right to know" has informed legislation and policies in various parts of the world.

${ }^{8}$ I say a little about this qualification at the end of this section.
} 
worthwhile. And this might lead the reader to wonder: isn't the Significant Interest view a mere sideshow in virtue of conceding that a subjective interest in genetic knowledge is worthwhile? In other words, if the Significant Interest view admits that an interest in genetic knowledge is worthwhile, why not base the argument for using an identity-release donor on what makes the interest worthwhile - namely the value of genetic knowledge - and not the (supposedly) derivative fact that donor-conceived people tend to have a subjective interest in acquiring it?

When I claim that a person's interest in genetic knowledge is (normally) worthwhile, I mean something very minimal indeed, namely that the interest is neither trivial (it is not like an interest in counting blades of grass) nor morally problematic (it is not like an interest in watching dog fighting). ${ }^{9}$ This minimal sense in which the interest is worthwhile is all that I need to get to the Significant Interest view off the ground. In other words, I do not need a substantive, positive account of the value of genetic knowledge to show that prospective parents have a weighty reason to use an identity-release donor.

This gives me two responses to the sideshow worry. First, even if the proper positive account of the value of genetic knowledge could directly ground an argument for my conclusion, there is still a good reason for offering the Significant Interest view. Claims about the value of genetic knowledge are controversial. So too is the conclusion that prospective parents have a weighty reason to conceive with an identity-release donor. If we can establish the conclusion by way of relatively uncontroversial premises - particularly without taking a stand on the value of genetic knowledge beyond claiming that an interest in it is worthwhile in my minimal sense then that would be something! People might disagree about the nature and extent of the value of genetic knowledge. But so long as they agree that people's interest in it clears a low bar - it is neither trivial nor morally problematic - then the Significant Interest view goes through.

The second response to the sideshow worry is more direct: the Significant Interest view is not a sideshow to a more direct argument based on the value of genetic knowledge because there is no such (plausible) argument. In other words: the proper account of the value of genetic knowledge cannot, in my view, plausibly be deployed to directly argue for the claim that prospective parents have a weighty reason to use an identity-release donor. I do not argue for this bold claim here. ${ }^{10}$ The point is just that the Significant Interest view is, as far as I'm concerned,

\footnotetext{
${ }^{9}$ Perhaps it is morally problematic in a subtler way? I consider this objection below, p. 17.

${ }^{10} \mathrm{I}$ argue for it in Chapter 4 of Groll forthcoming.
} 
the real deal: it provides the actual rationale for thinking that prospective parents have a weighty reason to use an identity-release donor.

Before we get to the view I want to make two preliminary points. First, by "genetic knowledge" I mean knowledge that would allow one to identify both of one's genetic parents and to find out some basic information about them including what they look like, what they are interested in, and their family histories. Having this kind of genetic knowledge is consistent with never actually meeting or interacting with one's genetic parents, although it will often be used to initiate contact. ${ }^{11}$ Second, I assume that keeping a donor-conceived person's status as a donorconceived person a secret from her is not a moral option: parents ought not to keep the secret. This is not something I can defend here. ${ }^{12}$

\section{The Profound Prudential Good view}

The Significant Interest view claims that there is a connection between having genetic knowledge and how well a person's life goes. The same is true for what I will call the Profound Prudential Good view. Since the two views are, at a high level of generality, making the same claim, I begin by highlighting the essential features of the Profound Prudential Good view so that I can be clear about how my view is different.

The Profound Prudential Good view maintains that genetic knowledge has non-optional, universal, weighty importance for well-being. ${ }^{13}$ What does this mean? Genetic knowledge is nonoptional (according to this view) in a metaphysically weak sense: as a matter of fact, given the world we live in and the kinds of creatures we are, acquiring genetic knowledge is a prudential good that cannot be replaced by some other (kind of) prudential good without significant loss. Implicit in this idea is that having genetic knowledge is prudentially valuable for basically everyone: it has universal importance. Perhaps it is not transparent to everyone that it prudentially matters - they might not think explicitly in terms of the prudential value of having

\footnotetext{
${ }^{11}$ See Ravitsky 2010 for discussion of what "genetic knowledge" might amount to in discussions about gamete donation. The notion of genetic knowledge I deploy is different than that deployed by David Velleman, who thinks of genetic knowledge in terms of actually being substantially acquainted with (indeed, ideally raised by) one's genetic parents (Velleman 2005 and 2008). Velleman's arguments are trenchantly criticized by Sally Haslanger 2009.

${ }^{12}$ I offer an argument for this claim in Chapter 1 of Groll forthcoming.

${ }^{13}$ I've coined the name for the view. The most sustained philosophical articulation of the view comes from David Velleman 2005 and 2008a, although for reasons I'll get to presently, he doesn't frame things in terms of well-being. There are hints of this kind of view in JL Nelson 1992.
} 
genetic knowledge - but its universal importance can be read off a vast array of cultural products and practices that emphasize the importance of knowing who your genetic parents are. ${ }^{14}$ Finally, something might have universal, non-optional prudential importance... but not very much. The Profound Prudential Good view, unsurprisingly, maintains that genetic knowledge is not one of those things: it has particularly weighty importance. To lack genetic knowledge is to lack something that matters a lot.

These three features of the Profound Prudential Good view - non-optionality, universality, and significant weight - are expressed in the idea that genetic knowledge is all but required for the kind of self-knowledge that is central to healthy identity formation. The basic thought is that someone who lacks genetic knowledge is missing a central source for accessing the kind of selfknowledge that allows them to make sense of themselves as the kind of person they are and the kind of person they could be. As Velleman puts it:

When adoptees go in search of their biological parents and siblings, there is a literal sense in which they are searching for themselves. They are searching for the closest thing to a mirror in which to catch an external and candid view of what they are like in more than mere appearance. Not knowing any biological relatives must be like wandering in a world without reflective surfaces, permanently self-blind.

Children denied a knowledge of only one biological parent are not entirely cut off from this view of themselves, but they are cut off from one half of it. Their estrangement even from one parent, or half-brothers and -sisters, must still be a deprivation, because it estranges them from people who would be familiar without any prior acquaintance, people with whom they would enjoy that natural familiarity which would be so revealing about themselves (Velleman 2005, 368).

If genetic knowledge has non-optional, universal, weighty importance then there is a tight connection between having genetic knowledge and flourishing. From there, it is easy to see the outline of an argument for the claim that people conceiving children with donated gametes have a weighty (and probably decisive) reason to use a known donor: in conceiving a child with anonymously donated gametes, the prospective parents effectively deprive the resultant child of a weighty, universal, non-optional prudential good.

Crucially, proponents of the Profound Prudential Good need not claim that people who lack genetic knowledge have lives that are not worth living, let alone flourishing. The claim,

\footnotetext{
${ }^{14}$ See Velleman 2005, 369 for some examples.
} 
rather, is just that a life without genetic knowledge is, to that extent, substantially disadvantaged or, to use Velleman's term, "truncated" even if, overall, the person's life goes quite well (and the person is overall very pleased to exist). ${ }^{15}$

But now one might wonder: if lives that lack genetic knowledge can be (well) worth living what objection could there be to creating such lives? Indeed, why not say that child who is created without access to genetic knowledge has nothing to complain about since their life is good enough and lacking genetic knowledge was a condition of their existence? Velleman's answer is that the threshold for permissibly creating a life is considerably higher than that life being one that is worth continuing. ${ }^{16}$ In other words, a human life that lacks $\mathrm{X}$ might be (well) worth continuing, but intentionally creating a human life that will lack $\mathrm{X}$ is impermissible. I cannot do full justice to Velleman's argument for this claim here, ${ }^{17}$ but the basic idea is simple enough: personhood has a value that demands respect and, in order to respect that value, "we are obligated, in creating human lives, to create ones in which that value is most likely to flower and least likely to be disfigured." 18 So, if you're going to bring someone into existence, you best insure that their life will not lack for goods the absence of which will disfigure the person's life, even if a life without those goods is well worth continuing. And if you think, as Velleman does, that having genetic knowledge is a good of this kind - because of its connection to forming one's identity - then intentionally creating someone who will lack it will not clear the bar for permissible procreation. ${ }^{19}$

My goal here is not to argue against the Profound Prudential Good view but simply to highlight its defining elements so as to differentiate it from the Significant Interest view. Nonetheless, I think it is important to briefly note that findings on donor conceived children and their families do not obviously support the idea that people who lack genetic knowledge are lacking a profound prudential good or living "disfigured" lives. To put it simply, the research that has been done on donor conceived children and their families suggests that the kids (and the

\footnotetext{
15 Velleman 2008a, 255.

${ }^{16}$ Velleman 2008b, 273-274.

17 A detailed account, and critique, of Velleman's argument and how it relates to the purported prudential badness of lacking genetic knowledge can be found in Schuman Forthcoming and Schuman Unpublished. I am indebted to Schuman's work in helping me think through these issues.

18 Velleman 2008a, 254.

${ }^{19}$ So proponents of this view can admit that once someone exists, it may be best for that person - and fully compatible with respecting them - to put them up for adoption since doing so is overall a benefit to them. Velleman $2008 \mathrm{a}, 252$.
} 
families) are alright: the families function well and the children do just fine. ${ }^{20}$ Moreover, among donor-conceived people that know they are donor-conceived, the desire to find one's genetic progenitor is not universal. ${ }^{21}$ This is not what one would expect to find if donor-conceived people were deprived of a profound prudential good, even granting that one's life can be well worth living without it.

Of course, these findings are consistent with the Profound Prudential Good view. Those that are not bothered by their lack of genetic knowledge could just be wrong about what matters. More plausibly, one might think that the studies in question, while accurately reflecting that donor conceived people do well enough, don't capture the ways in which their flourishing is impacted by a lack of genetic knowledge. That is, one might think that the studies have not, in effect, operationalized the disadvantage of lacking genetic knowledge. ${ }^{22}$ Or one might point to the fact that very many donor conceived people $d o$ seek out genetic knowledge as strong evidence that there is something very important missing from their lives.

I don't pretend, then, to have settled the matter here. My point is just that the sociology on donor conceived people and their families gives us reason to wonder whether the Profound Prudential Good view oversells the import of having genetic knowledge. Assuming that it does, the question is this: if we do not rely on the Profound Prudential Good view, is there another well-being based argument for using an identity-release donor?

\section{Well-being and significant interests}

The answer is "yes." Let's start with this thought about well-being:

Well-being and significant interests How well your life goes for you is partly (if not largely) a function of how successful you are in satisfying your significant, worthwhile

\footnotetext{
${ }^{20}$ And to the extent that there are findings to the contrary, this is usually because there are serious confounding factors at play such as (for the example) the fact that the parents didn't tell the child she was donor-conceived until well into the child's life. For a very clear and compelling overview of the social science see Golombok 2015.

${ }^{21}$ A 2009 study by Jadva et al. found that $34 \%$ of donor-conceived people who knew about their status as donorconceived people (almost always via parental disclosure) describe themselves as currently "indifferent" to that information. In a study done by Vanfruassen et al. (2003) of donor-conceived people being raised in lesbian households (all the kids were between 7 and 17 years old), over 50\% said they did not want any information about their donor. However, it is important to note that when asked why, some of these children cited concerns about hurting their social mother(s). Others, however, simply expressed no interest on their own behalf. Beeson et al. found that $82 \%$ of donor-conceived people that knew they were donor-conceived expressed an interest to "be in contact some day with their donor." (2419) I will come back to these statistics below (p. 10).

${ }^{22}$ This suggestion was made by David Velleman at a conference at NYU on the ethics of gamete donation and echoed by a number of donor-conceived people in the room.
} 
interests. If you satisfy a significant, worthwhile interest then, to that extent, your life goes better for you.

For ease of exposition, I'll call this the Well-Being Principle. By a significant interest I mean an interest that matters quite a lot to the person who has it. I enjoy peeling the labels off beer bottles in bars. Other things being equal, I will choose a beer bottle with a label so that I can peel the label off. Peeling-labels-off-beer-bottles-in-bars is an interest of mine. It is not a significant interest.

I offer no theory of what makes an interest "significant" except to say: 1) significance is scalar: one interest can be more significant than another and less significant than still another; and 2) the significance of an interest is partly a matter of the space, so to speak, it takes up in a person's mental economy (do they think about it a lot?) and the extent to which they organize their lives around it. More or less everyone has a lifelong, significant interest in being sated and reasonably well rested. Spouses tend to have a significant interest in fostering and maintaining meaningful relationships with each other. ${ }^{23}$ Significant interests play a structuring role in a person's life and self-conception.

Implicit in this brief account of what makes something a significant interest is that when I talk about a person having an "interest" I have in mind a subjective interest (i.e. something that a person is actually interested in satisfying) and not an objective interest (i.e. something that it is in a person's interest to have satisfied whether they are actually interested in it or not). Given this, the Well-Being Principle might now strike some as highly suspect: why think that satisfying a person's significant interests is, to that extent, good for them? But the Well-Being Principle does not say that satisfying whatever significant interests a person has is, to that extent, good for them. Rather, it restricts the relevant class of interests to worthwhile interests. I explained above (p. 3) what I mean by calling an interest "worthwhile": it is neither trivial nor morally problematic. Of course, what it means for an interest to be trivial or morally problematic is none too clear. I don't offer a general account of these terms, although I do return below to the question of whether the

\footnotetext{
${ }^{23}$ As these examples make clear, the principle does not distinguish between non-instrumental significant interests (the spousal interest) and instrumental significant instruments (the interest in being well-rested). One reason for this is that I want to remain neutral with respect to what kind of interest people's interest in having genetic knowledge is. Another is that I think with either kind of interest in view, the principle I articulate is plausible if by "instrumental interest" we mean rationally grounded instrumental interest, i.e. an instrumental interest that, roughly, is reliably causally connected to the satisfaction of a significant, non-instrumental interest.
} 
interest in genetic knowledge is either trivial or morally problematic. ${ }^{24}$ For now, the point is that by including the "worthwhile" qualification, I hope to make palatable the idea that a person's life goes better to the extent that they satisfy their significant interests, even when we understand those interests as "subjective interests".

The Well-Being Principle is, I think, intuitively attractive. Think about your own significant interests. To the extent that you have been able to satisfy them - and satisfying them might be an ongoing activity due to the nature of the interest - then you will, I suspect, think your life has gone better because of it. To the extent your attempts to satisfy them have been frustrated, you will feel, well, frustrated: "Here is something that has not gone well, or as well as it could, in my life! I have not succeeded when it comes to this thing that matters to me!" From a first-person perspective, satisfaction of significant interests seems central to how your life goes.

Moreover, as outsiders, we will surely endorse that first-person assessment if we think your significant interests are worthwhile, i.e. are non-trivial and not morally problematic. Indeed, to the extent that one's significant interests are worthwhile, they are, plausibly a substantial source of what gives one's life meaning. ${ }^{25}$ Some will think that satisfaction of one's significant interests contributes to one's well-being only if the interests are worthwhile. ${ }^{26}$ But we need not take a stand on that contentious claim here, since the Well-Being Principle makes a weaker claim: if your significant interests are worthwhile, then satisfying them makes your life go better. That is a very intuitive thought, whatever one thinks about how or whether satisfaction of a person's non-worthwhile significant interests contributes to their well-being.

With the Well-Being Principle in hand, we are in a position to forge an initial connection between having genetic knowledge and well-being:

1. If someone satisfies a significant, worthwhile interest then, to that extent, their life goes better for them.

2. There are some people for whom acquiring genetic knowledge is a significant, worthwhile interest.

\footnotetext{
24 See p. 13

25 The Well-Being Principle, which weds subjective interest to something like "objective worthwhileness", takes its inspiration from Susan Wolf's conception of meaning according to which, "meaning arises when subjective attraction meets objective attractiveness" (Wolf 2010, 9). Having said that, I think the principle could easily be taken on by those who ascribe to a preference or desire-based theories of well-being since it partially articulates the heart of their views. According to these views (roughly), what makes something good for you is that it satisfies some noninstrumental interest (desire, preference) of yours. So satisfying your non-instrumental, worthwhile interests will make your life go better for you. And so too will satisfying your worthwhile, instrumental interests inasmuch as they cause you to satisfy your non-instrumental, significant interests.

${ }^{26}$ Indeed, this is what I think. I think it's what I think anyhow.
} 
3. So, if those people acquire genetic knowledge, then their lives go better for them (to that extent).

This argument for a connection between genetic knowledge and increased well-being posits no special connection between acquiring genetic knowledge and well-being. Rather the connection between genetic knowledge and well-being falls out of a more general, very simple story about how well-being is connected to satisfying one's significant, worthwhile interests whatever they may be. To see this, notice that we could run the argument for an entirely different significant, worthwhile interest that someone might have:

4. If someone satisfies a significant, worthwhile interest then, to that extent, their life goes better for them.

5. There are some people for whom competing to build cars with the loudest possible stereo - what is known as "dB drag-racing" 27 - is a worthwhile, significant interest. ${ }^{28}$

6. So, if those people compete to build cars with the loudest possible stereo, then their lives go better for them (to that extent).

At this point, the reader might feel let down. If all I mean by asserting a connection between having genetic knowledge and well-being is that there are some people for whom acquiring genetic knowledge is prudentially good - in virtue of those particular people having a worthwhile significant interest in acquiring genetic knowledge - then there is nothing to object to. I have not shown that there is anything resembling a deep connection between genetic knowledge and well-being. Indeed, for all I have said, I could just as easily have written a paper about the connection between well-being and $\mathrm{dB}$ drag-racing or, indeed, any other idiosyncratic worthwhile interest.

An interest in $\mathrm{dB}$ drag-racing is a very idiosyncratic significant interest. Other examples of idiosyncratic significant interests might include dog breeding, stamp collecting, visiting every Major League Baseball stadium, being a practicing Jew, or being a foster parent. This mixture of examples is meant to illustrate that some idiosyncratic abiding interests are likely to be weightier than others. For my purposes, what makes an interest idiosyncratic is, simply, its frequency.

\footnotetext{
${ }^{27}$ See Segal 2004.

${ }^{28}$ Some might think this interest is trivial and so not worthwhile. I disagree: people who engage in $\mathrm{dB}$ drag-racing are creative problem solvers with impressive technical skills who form communities in which friendships and other valuable forms of association arise. But really, my use of this example is meant in part to illustrate how low I am setting the bar for an interest to count as "worthwhile". It is another way of showing that the Significant Interest view does not depend on a strong, positive view of the value of genetic knowledge.
} 
But of course, not all interests that people have are idiosyncratic. Indeed, some are (very nearly) universal. Following (and slightly modifying) Rawls $(2009,54)$, I will call these primary interests. Primary interests are interests that we can safely assume people (will) have no matter what other interests they have. Primary interests are always significant interests.

If genetic knowledge were a (worthwhile) primary interest then there would be a fairly deep connection between having genetic knowledge and well-being: we would have identified a (near) universal ingredient of well-being. I have, however, already ruled out arguing for a connection between well-being and genetic knowledge on the grounds that the latter has (near) universal importance (let alone non-optional, weighty importance). But now it looks like I have a problem. For if the interest in genetic knowledge is merely idiosyncratic, then it seems I am stuck with the very weak conclusion that an interest in genetic knowledge relates to well-being in much the same way the interest in $\mathrm{dB}$ drag-racing does.

But that is not right. To see why, consider what follows from the fact that an interest is a primary interest: it is highly foreseeable that any given person has it. The same is not typically true of idiosyncratic interests: it is not at all foreseeable that anyone you happen to meet has a significant interest in $\mathrm{dB}$ drag-racing. Indeed, that interest is so idiosyncratic that it would be irrational to predict that any given person has it. In general, then, the fact that an interest is idiosyncratic makes it irrational to predict that any given person has it and especially irrational to predict that any given young child will come to have it.

The idiosyncratic interest in acquiring genetic knowledge, however, is an exception. It is a rare idiosyncratic interest where, with just one bit of information, it is rational to predict that someone has it or will have it. That information, of course, is that the person is a donorconceived person. What makes the prediction rational is just that it is very common, though not universal, among donor-conceived people (at least) to be significantly interested in acquiring genetic knowledge. ${ }^{29}$ In support of this claim consider three bits of evidence: ${ }^{30}$

1. There is burgeoning interest in online forums and registries for donorconceived people. Consider the Donor Sibling Registry, which L. Shanner and R. Harris $(2012,61)$ describe as the "most important non-governmental, voluntary registry and matching service in the world." It was created in 2000. In 2005, "the DSR reported 4,000 families registered [...]; in 2006, over 7000

\footnotetext{
${ }^{29}$ And maybe among the population at large in which case it would not be an idiosyncratic interest. Nor would it be a universal interest. It would just be a very common interest... which I suspect it is.

${ }^{30}$ I offer another bit evidence below, p. 17.
} 
[...]; in 2009, 24,000 registrants [...]; in July 2011, 31,248 registrants [...];

By November 2012...over 38,300 registrants." 31

2. In a 2003 study, researchers asked parents who had conceived with an identity-release donor and had either disclosed or planned to disclose this fact to their (adolescent) child, what they thought their child's reaction would be toward learning they were donor-conceived and that the identity of the donor was available to them. The researchers report that:

Many [parents] already knew how the child felt. Most parents expected or knew that their child felt at least neutral, if not moderately positive, about the donor. Among the few parents who anticipated negative feelings, it was when the child had not yet been told about his or her donor conception. Some thought their child would have concerns and/or be anxious about the donor, such as what he would be like and whether he would be willing to meet him or her and like him or her, nevertheless similar numbers also reported that their child looked forward to possible meetings. Most of all, however, the overwhelming response from the children was curiosity about the donor (Scheib, Riordan and Rubin 2003, 1124).

3. In a 2009 study of donor-conceived people whose status was disclosed to them, only $21 \%$ described themselves as currently "indifferent". The majority (69\%) described themselves as "curious" (Jadva et al 2009, 1914).

4. In a 2014 study, $82 \%$ of donor-conceived people who knew they were donorconceived expressed an interest to "be in contact some day with their donor" (Beeson, Jennings and Kramer 2011, pp.).

This is pretty good evidence that having genetic knowledge is a very common interest among donor-conceived people, even if it is not universal. It looks like a good bet that any given donorconceived person either has or will develop a significant interest in having genetic knowledge. It is different, in that respect, from idiosyncratic interests like stamp collecting, dog breeding, or $\mathrm{dB}$ drag-racing: other things being equal it is not a good bet that someone is interested in them. And, if they are young children, it is certainly not a good bet that they will be interested in those things. ${ }^{32}$ These idiosyncratic interests are not foreseeable interests. The interest in having genetic

\footnotetext{
${ }^{31}$ Although John Appleby in conversation tells me that many of the people that have signed up for the DSR are parents of donor-conceived children, and not the DC people themselves. In fact, some evidence (Freeman et al., 2009) suggests that parents account for the majority of users.

${ }^{32}$ Parents, of course, play a huge role in shaping what interests a child will have. So perhaps they are in a position to make different bets than a stranger about what interests their child will develop. I consider this possibility below.
} 
knowledge, on the other hand is a foreseeable, significant interest at least for donor-conceived people. Moreover, it is worthwhile in the minimal sense I intend: it is neither trivial nor morally problematic. $^{33}$

In light of this, what can we say about the connection between the interest in having genetic knowledge and the well-being of donor-conceived people? In the very least, there is a general connection between them. In general, donor-conceived people are significantly interested in genetic knowledge. And, as the Well-Being Principle tells us, satisfying one's worthwhile significant interests contributes to one's well-being (if they are worthwhile). So there is a general connection between donor-conceived people's well-being and their acquiring genetic knowledge.

This connection is not as tight as it would be if the interest in genetic knowledge were (near) universal: Then there would be a connection between (almost) everyone's well-being and having genetic knowledge. Moreover, the connection I've argued for is not as deep as it would be if genetic knowledge had non-optional, weighty importance: Then we would be able to say something about why the interest in genetic knowledge is significant and foreseeable at least among donor-conceived people. In other words, the account I have offered of the connection between having genetic knowledge and the well-being of donor-conceived people is somewhat weak. However, it is strong enough in the following sense: it is enough to ground the argument that prospective parents who plan to conceive via gamete donation have a weighty reason to conceive with an identity-release donor. And this "strong enough" approach is precisely what I am going for. We don't need to defend the (implausible in my view) claim that having genetic knowledge is profoundly important in order show that prospective parents have a weighty reason to conceive with an identity-release donor. It is enough that, as a matter of fact, an interest in having genetic knowledge is a worthwhile, foreseeable interest (at least for donor-conceived people). Such, anyway, is what I aim to show next.

\section{Parents \& their children's future significant interests}

How do we get from the idea that acquiring genetic knowledge is a worthwhile, foreseeable interest of donor-conceived people to the conclusion that parents have a weighty reason to conceive with an identity-release donor? It starts with a very basic assumption: parents

\footnotetext{
${ }^{33}$ I have not argued for this. I address it below, p. 13.
} 
have a special, weighty obligation to promote their children's overall well-being. Something like this assumption is undeniable. ${ }^{34}$ Even so, it is not entirely clear what it amounts to since it tells us nothing about when parents have the obligation and what, exactly, its object is, i.e. well-being at a time or across a life. To see this, consider how we might unpack the assumption:

Parents have a (special, weighty) obligation [at all times of the child's life//only when the child is young], to promote the child's overall well-being [across the child's life//only when the child is young].

Rather than considering all the possibilities here, we can help ourselves to an uncontroversial version of it:

Parents have a (special, weighty) obligation at least when the child is young, to promote the child's overall well-being across the child's life.

A key responsibility of parents is to prepare their children for adult life. A parent that is focused on promoting their child's well-being only when the child is young plausibly should accede to all (or at least many) requests for another serving of ice cream. A total lack of concern about developing traits, habits, or skills that will stand the child in good stead for the future would be perfectly appropriate if the child does not have a future beyond childhood. But if the child likely does have a future beyond childhood, a central responsibility of parents is to make decisions now to put the child in a position to succeed as an adult.

Meeting this obligation is, of course, one of the central challenges of parenthood. But the Well-Being Principle gives us some guidance for how parents can go about meeting it. Suppose, for example, I know that my child will develop a serious, significant interest in $\mathrm{dB}$ drag-racing no matter what I do. ${ }^{35}$ The Well-Being Principle tells me that, other things being equal, satisfying this interest will make my child's life better. Now, we could imagine a scenario where I reasonably think that all things considered, satisfying this interest will make her life worse perhaps we live in a society where dB drag-racers are severely persecuted. But suppose it is not reasonable for me to believe that satisfying this particular future significant interest of my child will make her life worse overall. Then the Well-Being Principle, combined with the assumption that I have a special, weighty obligation when my child is young to promote her overall wellbeing across her life, tells me that I have a weighty reason to prepare the ground for my child to

\footnotetext{
${ }^{34}$ But only if we remember that by "parent" I mean "normative parent". See above n. 4.

${ }^{35}$ Of course, this is wildly implausible. But that doesn't matter for now. I return to the issue of parental influence on significant interests below, p. 15.
} 
succeed in satisfying this significant interest (by, perhaps, signing her up for engineering camps or taking her to $\mathrm{dB}$ drag-races). More generally, our assumption about parents' duty to promote their children's well-being when combined with the Well-Being Principle implies that:

Future Significant Interests Principle Parents have a weighty reason to prepare the ground, when a child is young, for their children to satisfy the worthwhile, future significant interests of the child unless the parents reasonably believe doing so will make the child less well-off overall.

How should parents go about acting on the Future Significant Interests Principle? The toy example I just offered might suggest that the principle gives very little practical guidance. After all, parents cannot know, with any degree of confidence, that their child will develop a significant interest in $\mathrm{dB}$ drag-racing. More generally, parents are largely in the dark with respect to what their child's future significant interests will be. Indeed, one of the great sources of joy and anxiety in parenting is wondering about, and watching, what kind of person your child will be, what will move and motivate her, what pursuits and passions will shape her life.

But it is easy to overstate the uncertainty that parents face about their child's future significant interests. For, as we saw above, there are different kinds of future significant interests: some are foreseeable while others are not. It is highly foreseeable that a child will have interests that are in the set of primary interests. There are other interests that are not universal but are sufficiently common among the general population that it is rationally foreseeable that a child will develop them as well. Raising a family might be an example: It is not a (near) universal interest, but it is a good bet that a child will develop it. And then there are interests that, perhaps, are not common among the general population but are nonetheless rationally foreseeable given some set of circumstances - these are idiosyncratic foreseeable interests. The interest in having genetic knowledge among donor-conceived people is an example of the last. ${ }^{36}$ So for prospective parents of donor-conceived people (at least) it is rationally foreseeable that their child will develop a significant interest in acquiring genetic knowledge.

The Future Significant Interests Principle, then, isn't a true-but-practically-idle principle. Parents $d o$ have a good idea of what some of their children's future significant interests will be and so they reasonably can, with respect to many of those interests, prepare the ground for the

\footnotetext{
${ }^{36}$ Although if what I said in $\mathrm{n} .29$ is correct, then it is an example a very common, though not universal, interest. Either way, my argument goes through.
} 
children to satisfy them. The Future Significant Interests Principle tells them to do so (unless they reasonably think doing so will be deleterious to the child's overall well-being).

The upshot is that if having genetic knowledge is a significant, foreseeable interest at least for donor-conceived people, then parents of a donor-conceived person have a weighty reason, when the child is young, to make decisions that will prepare the ground for the child to satisfy her likely future interest in having genetic knowledge (unless the parents reasonably think doing so will be deleterious to the child's overall well-being).

What does this have to do whether prospective parents have a weighty reason to avoid conceiving a child with an anonymous gamete donor? After all, when that decision is being made there is, as yet, no child to whom one is obligated. How then could the Future Significant Interests Principle apply to them? The answer is that the prospective parents intend (indeed hope), that they will be obligated to their future child, whoever it will be, in the way described by the Future Significant Interests Principle. Of course, they do not articulate the principle to themselves. But in planning to conceive a child, prospective parents are knowingly and voluntarily intending to take on a role that is partly defined in terms of having a weighty, special obligation to promote the well-being of the (future) child. They see (and embrace) the obligation that is in the offing. And this obligates them to take steps now to put themselves in the position to meet that obligation. The general obligation they will have to the child requires that they take steps now so that they are in a position to fulfill the obligation they see coming (and fully embrace). So, if they have a special, weighty reason to help the child, when she is young, to satisfy a foreseeable future significant interest in acquiring genetic knowledge, then they have special, weighty reason to decide now to use an identity-release donor. This is because doing so

will enable them, as parents, to meet the obligation articulated by the Future Significant Interests Principle when the child exists.

\section{Objections}

\subsection{Objection 1: More harm than good?}

I have claimed that prospective parents have a weighty reason to conceive with an identityrelease donor unless they reasonably think doing so will be deleterious to the child's overall well-being. A critic might claim that it $i$ in general reasonable to think that using an identityrelease donor will be overall deleterious to the child's overall well-being. If that's right, then in 
general, prospective parents don't have a weighty reason to use an identity-release donor (at least as far as my argument is concerned).

This objection puts the burden of proof clearly on the objector to explain why, in general, parents could reasonably believe that aiming to satisfy the (likely, future) significant interest in having genetic knowledge via use of an identity-release donor will be overall deleterious to their child's well-being. The bit in italics is important: it is not hard to see how satisfying a person's interest in acquiring genetic knowledge by helping them track down an anonymous donor might not go well for the donor-conceived person. Anonymous donors are sometimes happy to be identified, but sometimes they are not. ${ }^{37}$ And this can lead to very difficult situations for donorconceived children and their families. But these situations are not likely to occur with identityrelease donors who agreed in advance to have their identities made available to the donorconceived child. Of course, people can change their minds. And even if they don't, contact might not go well. But on the whole, it is safe to assume that identity-release donors are willing (in some cases perhaps waiting) for their genetic offspring to get in touch, particularly if there are policy mechanisms in place to facilitate contact. Indeed, the evidence we have about contact between donor-conceived people and donors suggests that it is usually (though not universally) a positive experience. ${ }^{38}$

\subsection{Second objection: the interest in genetic knowledge is not worthwhile}

I have claimed throughout that a donor-conceived person's significant interest in acquiring genetic knowledge is worthwhile. But I have said nothing to support this claim. Maybe we should see the interest in having genetic knowledge as either trivial or morally problematic. To know whether it is trivial, we would need to say something about what, in general, makes an interest trivial. I don't want to do that. Instead, I want to point out that an interest in genetic knowledge seems no worse off - with respect to being trivial - than most of the other interests I have used as examples of worthwhile, significant interests: an interest in $\mathrm{dB}$ drag racing, or stamp collecting, or visiting Major League Baseball stadiums. Maybe some will happily say

\footnotetext{
${ }^{37}$ See, for example, Freeman et al. 2012, 260-61

${ }^{38}$ Freeman et al. 2014, reporting on a public program in Victoria, Australia to "operationalize the complex process of linking donor relations" : "The early indications are that contact between donor relations often has positive outcomes for all involved," (285) and "So far, there have been few reports of negative outcomes of contact involving donors or half-siblings, with those who meet tending to get on well and stay in touch" (286).
} 
these are all trivial interests, akin to an interest in simply counting blades of grass. I prefer a generous conception of which activities or pursuits are non-trivial, one that includes stamp collecting, game playing, and learning who one's genetic parent is. People find, and create, genuine meaning in all kinds of pursuits that might look like a total waste of time when viewed narrowly ("What's the point of tracking down pieces of paper and putting them in a book?"). An account according to which an interest in genetic knowledge is trivial will, I suspect, have a hard time saving a huge number of very human interests from the charge of triviality.

The claim that an interest in genetic knowledge is morally problematic, however, is more plausible. If by "morally problematic" we mean something like "frankly immoral" or "cruel" or "morally reprobate" or "blameworthy" then we can safely assume that having an interest in genetic knowledge is (in normal cases) not morally problematic. But this is not the notion of "morally problematic" I imagine the objection invoking. Instead, I have in mind a far broader notion wherein an interest is morally problematic if it evinces and entrenches a morally problematic set of practices and attitudes, though not necessarily in a way that makes the interest holder blameworthy or cruel or morally reprobate or frankly immoral.

Someone might think that a significant interest in having genetic knowledge is morally problematic in this sense because it evinces and entrenches a bionormative prejudice according to which genetic ties - and family forms based on genetic ties - are of great significance (when they're not). ${ }^{39}$ Melo-Martin expresses this line of thought very nicely:

Emphasizing the importance of genetic relationships might...encourage problematic beliefs about the superiority of biological families. ... If emphasizing the importance of genetic information has the effect of idealizing the biological family, then it may actually undermine the interests of donor-conceived individuals. (Melo-Martin 2013, 33)

The morally problematic nature of the interest in genetic knowledge, on this view, might be likened to the way in which certain gendered interests are morally problematic - the interest, perhaps, that some women have to conform to a certain conception of sexual attractiveness or the interest, perhaps, that some men have to conform to a certain conception of masculinity. These gendered interests reflect, and result from, deeply problematic societal structures and attitudes. We are not apt to blame individuals for having these interests. Indeed, we might think it is not only understandable that they have them, but also rational, given the options available to them.

\footnotetext{
${ }^{39}$ A version of this idea can be found in Witt 2005 \& 2014, Haslanger 2009, Melo-Martin 2013, and Appleby \& Karnein 2014.
} 
Even so, we will acknowledge that it would be best if the structures and attitudes were different so that the interests in question did not so readily arise as live possibilities, let alone desirable or rational ones. If we could choose whether people have the interest and satisfy it or don't have the interest at all we would choose the latter. This is a mark of the interest being morally problematic in the relevant sense. If there is good reason to think that the interest in genetic knowledge is morally problematic in this way, then I cannot deploy the Well-Being Principle to argue for a general connection between acquiring genetic knowledge and well-being: The Well-Being Principle only speaks to a connection between worthwhile interests and well-being.

This is a serious objection to my argument. One strategy for responding to it would be to grant that an interest in genetic knowledge is morally problematic in the intended sense, but then drop the "worthwhile" clause from the Well-Being Principle. This is not my preferred strategy. Instead, I would rather show that an interest in genetic knowledge is not (usually) morally problematic. But this is not something I will attempt to do here - so the objection will go unanswered. ${ }^{40}$ What I will say is that the idea that an interest in genetic knowledge is akin to misogynistic interests (for example), which are clearly the result of prejudiced or deeply problematic attitudes, beliefs, emotions etc. strikes me as a very strong view indeed. The interest in genetic knowledge among donor-conceived people is, I think, more akin to an interest in $\mathrm{dB}$ drag-racing or breeding dogs in the sense of being one avenue among many that a person can follow as part of building a meaningful life. It is far less idiosyncratic than those interests: unlike those other interests, many people build meaningful lives at least in part through an interest in creating, maintaining, learning about genetic connections between themselves and other people particularly immediate genetic family. ${ }^{41}$ But it is like the more idiosyncratic interests in being one way of forging meaningful connections. But I have given no argument for this view.

\subsection{Third objection: Parental influence and Foreseeable Interests}

I have claimed that a donor-conceived person's interest in having genetic knowledge is foreseeable. One might think this is true in one sense, i.e. for any given donor-conceived person,

\footnotetext{
${ }^{40} \mathrm{I}$ offer a full answer in a work in progress.

${ }^{41}$ This idea is explored by J Lindemman Nelson $(1992,199)$ who proposes the "genetic narrative" view of the family. Nelson seems to suggest, like Velleman, that access to these kinds of stories is necessary (or something close to it) for healthy identity formation or that these kinds of stories are, or ought to be, privileged. That is where I disagree.
} 
it is a good bet that she will develop a significant interest in having genetic knowledge. The implicit claim is that because the interest is foreseeable in this sense, parents of donor-conceived people should assume that it is one their child is very likely to have. But surely this paints the wrong picture of the relationship between parents and their children's interests. I have, in effect, been imagining parents asking themselves "What will my child's future significant interests be?" as though this is a purely epistemic question. Talk of interests being "foreseeable" encourages this reading. It suggests that what a child's future significant interests will be is independent of the answers the parents come up with. Asking "What will my child's future significant interests be?" is, according to this picture, like asking, "What will the weather be like tomorrow?" How $I$ answer the question plays no role in determining the actual answer.

But parents play a huge role in determining what significant interests their children will have. And this means that while some interests might be very common indeed, that doesn't necessarily give parents good reasons to think their child will develop such interests. Consider, for example, what is surely a foreseeable future interest of most children: being involved in a religious community. But children of parents who practice no religion are very likely not to have any significant interest in being involved in a religious community precisely because their parents had no such interest (Bengston 2017). To the extent that parents know this - and indeed intentionally inculcate a lack of interest in any particular religion - they have no reason to do anything (when the child is young) to help them satisfy an interest that their child, in fact, is very unlikely to have (even though, in general, it is a highly foreseeable interest). The same might be true with respect to the foreseeable interest of having genetic knowledge: If parents emphasize that having genetic knowledge is thoroughly unimportant then, perhaps, it is very likely their child will believe it is unimportant and so develop no significant interest in it. These parents, then, have no reason to do anything when the child is young to help them satisfy an interest in genetic knowledge and so no reason to use an identity-release donor (at least as far as the Significant Interest view is concerned). Call this the Parental Influence Objection.

One response to the Parental Influence Objection is to claim that parents ought not, to the best of their abilities, influence a child's future significant interests in this way. Whatever significant interests a child develops as she matures into adulthood should be, in some sense, up to her. The parents should, in other words, keep the child's future as open as possible. It would 
be a wrongful imposition on the child's future autonomy, then, to actively work to inculcate in the child a complete lack of interest in having genetic knowledge. ${ }^{42}$

This response is open to critique on at least two fronts. The first is practical: Parents' influence on their children's values, interests etc. is simply unavoidable. Indeed, attempting to avoid it really is just another way of shaping future values, interests etc. ${ }^{43}$ The second critique is moral: Even if shaping is, to some extent, avoidable (and surely to some extent it is), parents are entitled to shape at least some of a child's interests and values in some ways. As Brighouse and Swift have argued, some distinctive goods - for both children and parents - can only be realized in the context of intimate family bonds and part of the way those bonds are inculcated is by parents sharing their interests with their children. ${ }^{44}$ (Brighouse and Swift, 2014, ch 6)

A more compelling response to the Parental Influence Objection begins by granting the (painfully) obvious point that parents play a huge role in shaping the future significant interests of their children. But it directs our attention to another (painfully) obvious point: parental influence doesn't play a role in shaping all of a child's future significant interests. There are some interests that a child will likely develop in spite of, indeed possibly partly because of, permissible parental influence. Children often develop interests, passions, values, and goals that are very different from their parents (sometimes to the consternation of their parents). In other words, we should distinguish between Parentally Influenced Interests and Non-Parentally Influenced Interests. The distinction is not a sharp one. The true account of how a child developed a particular interest will usually appeal to (intentional) parental influence among many other, non-parental influences. Even so, I think it is clear that there are interests a person is likely to develop no matter what permissible parental influencing takes place.

An interest in genetic knowledge is plausibly one such interest: a donor-conceived person is likely to develop a significant interest in having genetic knowledge no matter what his parents permissibly do to try to make him uninterested. The "permissibly" is very important. We can imagine a futuristic scenario where parents are able to directly manipulate the brains of their

\footnotetext{
42 This is a version of Feinberg's well-known view that children have a right to an "open future" (1994). Matthew Clayton $(2006,2015)$ defends what he calls "parental anti-perfectionism" according to which, "it is not a legitimate aim for those responsible for raising a child to enroll her into particular comprehensive practices" (2015, p. 130).

${ }^{43}$ Mills 2003. She also makes a series of other criticisms of the Open Future Argument.

${ }^{44}$ I don't pretend my brief responses to Feinberg or Clayton-like views settle the matter. Clayton's development and defense of parental anti-perfectionism is detailed and subtle. A proper reckoning with it is beyond the scope of this paper. Of course, if Clayton is right then that provides another route for responding to the Parental Influence Objection.
} 
children so as to inculcate certain interests and not others. In such a scenario, parents could directly influence (well, cause) children not to develop an interest in genetic knowledge. Back in the real world, some parents of donor-conceived children can quite reliably (though not certainly) ensure that their child does not develop a significant interest in having genetic knowledge by, for example, not telling the child that she was conceived via gamete donation. ${ }^{45}$ So to claim that donor-conceived people are largely immune from parental influence when it comes to developing an interest in genetic knowledge is not to suggest that there is nothing parents could possibly do to reliably influence the child with respect to this interest. The claim, rather, is that using these forms of "influence" is impermissible. And then the further implicit claim (which I'm now making explicit) is that no permissible form of influence is likely to result in the child not developing a significant interest in having genetic knowledge.

This is, of course, an empirical conjecture. But I think it is highly plausible. Facts about how children are conceived (i.e. that sperm and eggs are required); plus the fact that most kids have both genetic parents raising them; plus whatever cultural forces push in the direction of suggesting that knowing your genetic parentage matters; all of this conspires to make the question, "Who is my (other) genetic parent?" almost unavoidably of interest at least to children who do not know their complete genetic parentage. ${ }^{46}$ Not totally unavoidably - some donorconceived people do not seem interested in the question. But it is, I think, a very good bet that any given donor-conceived person will be interested no matter what their parents permissibly do to try to make them uninterested.

If that is right, then we can modify the Significant View to get around the Parental Influence Objection. What matters is not just that having genetic knowledge is a foreseeable, significant worthwhile interest of donor-conceived people, but also that whether a donorconceived person has it is largely immune to permissible parental influence.

\section{Implications}

What does all this mean for the practice of anonymous gamete donation? As I have emphasized throughout, the Significant Interest view is meant to establish that parents

\footnotetext{
${ }^{45}$ As, indeed, most parents of donor-conceived people do not. See Golombok 2015, 99-102.

${ }^{46}$ As Golombok 2015 (100) notes, one reason parents are hesitant to tell children they are donor-conceived is that, "They were concerned about not being able to answer their child's inevitable question: 'If you are not my biological parent, then who is?"' (emphasis added).
} 
conceiving via gamete donation have a weighty reason to use an identity-release donor. It might turn out that that reason is outweighed by other considerations. ${ }^{47}$

I don't have space to consider just what those other reasons might be or whether, taken singly or jointly, they provide at least some parents with decisive reason to use an anonymous donor. What I want to do instead is highlight a difference between two kinds of consideration that might be thought to countervail the reason I have identified to use an identity-release donor.

Consider the fact that someone in France, for example, might well find using an identityrelease donor especially burdensome because anonymous donation is legally mandated. Now this burden would probably not justify using an anonymous donor if the resulting person was being denied a profound prudential good or having a right violated. But the Significant Interest view doesn't make either of those claims. Instead it claims that the resulting child is likely to have a significant subjective interest frustrated. Now this is not nothing! But even so: lots of people have some of their significant subjective interests frustrated. It is not the end of the world. So perhaps the burden of using an identity-release donor in France, for example, produces a reason that countervails the reason to use an identity-release donor posited by the Significant Interest view.

This countervailing reason - if it is one - is extrinsic to the practice of donor conception. That is, there is nothing about donor conception itself that generates the countervailing reason. Rather, it is generated by the way donor conception is dealt with in France. The potentially countervailing reason would be removed altogether by changing France's regulatory framework. The same is true for other countervailing reason that are related to cost or access.

These extrinsic countervailing reasons can be contrasted with intrinsic countervailing reasons. These are reasons that at least some parents will have to use an anonymous donor that are not the result of a particular regulatory or institutional framework for donor conception, but instead will be present in any feasible institutional framework for donor conception. Consider, for example, that some prospective parents might themselves have a significant (subjective) interest in not using an identity-release donor, perhaps because they want the donor to play as little a role in their parental life and the life of the child as possible.

\footnotetext{
${ }^{47}$ This is not just an issue for my view, but the other views as well. Even if having genetic knowledge is a profound prudential good or children a have a right to genetic knowledge, there's still the question of whether competing considerations give prospective parents all things considered reason to use an identity-release donor.
} 
The point of making the distinction between intrinsic and extrinsic countervailing reasons is to make clear that at least some of the reasons against using an identity-release donor are a function of systems that can be changed. Extrinsic countervailing reasons are a function of contingent features of the structure of identity-release donation practices in places where anonymous donation is the norm. They are reasons that are a function of how the structure of donor conception works in a particular place at a particular time. If the argument I have offered for using an identity-release donor is a good one, then we have at least some reason to think those systems should be changed. What this means is that many people who are looking to conceive via gamete donation now may well be all things considered justified in using an anonymous donor. But at least some of the reasons for thinking they are so justified are consistent with the thinking we should move toward a system where, in the future, prospective parents will not be.

Whether those prospective parents will be justified in using an anonymous donor depends on what intrinsic countervailing reasons there are and how they weigh against the reason I have identified to use an identity-release donor. ${ }^{48}$ Absent answers to these questions, the argument in this paper falls short of showing that prospective parents (generally) have a decisive reason to use an identity-release donor. It does however show that there is a weighty reason prospective parents that plan to conceive via gamete donation must take into account.

\section{Works Cited}

Appleby, J. B. and Karnein, A. J. 2014. On the moral importance of genetic ties in families. In: Relatedness in Assisted Reproduction: Families, Origins and Identities (pp. 79-96), T. Freeman, S. Graham, F. Ebtehaj and M. Richards (eds.). Cambridge, England: Cambridge University Press.

Beeson, D. R., Jennings, P. K., \& Kramer, W. 2011. Offspring searching for their sperm donors: how family type shapes the process. Human reproduction, 26(9): 2415-2424.

Bengtson, V. L. 2017. Families and faith: How religion is passed down across generations. Oxford, England: Oxford University Press.

Clayton, M. 2015. Anti-perfectionist childrearing. In: The Nature of Children's Well-Being (pp. 123-140), Alexander Bagattini and Colin Macleod (eds.). Springer, Dordrecht.

\footnotetext{
${ }^{48}$ The answers are, I think, "It depends on what grounds the interest" and "No." This is something I argue for in
} Groll forthcoming 
Clayton, M. 2006. Justice and legitimacy in upbringing. Oxford, England: Oxford University Press.

Dworkin, G., 2005. Moral paternalism. Law and Philosophy 24(3): 305-319.

Dworkin, R., 1990. Foundations of liberal equality. University of Utah Press.

Feinberg, J. 1994. The Child's Right to an Open Future. In Freedom and fulfillment:

Philosophical essays (pp.76-97). Princeton, NJ: Princeton University Press.

Freeman, T., Bourne, K., Jadva, V., \& Smith, V. 2014. Making connections: contact between sperm donor relations. In Relatedness in Assisted Reproduction: Families, Origins and Identities (pp. 270-295), T. Freeman, S. Graham, F. Ebtehaj and M. Richards (eds). Cambridge, England: Cambridge University Press.

Freeman, T., Appleby, J., \& Jadva, V. 2012. Identifiable donors and siblings: implications for the future. In: Reproductive donation: Practice, Policy, and Bioethics (pp. 250-269), M. Richards, G. Pennings, and J.B. Appleby (eds). Cambridge, England: Cambridge University Press.

Freeman, T., Jadva, V., Kramer, W. and Golombok, S. 2009. Gamete donation: parents' experiences of searching for their child's donor siblings and donor. Human Reproduction, 24(3): 505-516.

Frith, L. 2001a. Gamete donation and anonymity: the ethical and legal debate. Human reproduction. 16(5): 818-824.

Frith, L. 2001b. Beneath the Rhetoric: The Role of Rights in the Practice of Non-Anonymous Gamete Donation. Bioethics 15(5-6): 473-484.

Golombok, S., 2015. Modern families: parents and children in new family forms. Cambridge, England: Cambridge University Press.

Groll, D. Forthcoming. The Need to Know. New York, NY: Oxford University Press

Guichon, J.R., Mitchell, I. and Giroux, M. eds., 2012. The Right to Know One's Origins: Assisted Human Reproduction and the Best Interests of Children. Brussels, Belgium: Academic and Scientific Publishers nv).

Harris R. and Shanner L. 2012. Seeking Answers in the Ether: Longing to Know to One's Origins is Evident from Donor Conception Websites. In: The Right to Know One's Origins: Assisted Human Reproduction and the Best Interests of Children (pp. 57-72), J.R. Guichon, I. Mitchell, and M. Giroux (eds.). Brussels, Belgium: Academic and Scientific Publishers nv).

Haslanger, S. 2009. Family, Ancestry and Self: What is the Moral Significance of Biological Ties? Adoption \& Culture 2.1: 91-122. 
Jadva, V., Freeman, T., Kramer, W. and Golombok, S. 2009. The experiences of adolescents and adults conceived by sperm donation: comparisons by age of disclosure and family type. Human Reproduction, 24(8): 1909-1919.

Jadva, V., Freeman, T., Kramer, W., \& Golombok, S. 2010. Experiences of offspring searching for and contacting their donor siblings and donor. Reproductive BioMedicine Online, 20(4): 523 532.

W. Kramer. 2016. Sperm Donors Who Wish To Remain Anonymous Just Shouldn't Donate. Huffington Post, https:/www.huffingtonpost.com/wendy-kramer/sperm-donors-who-wish-tob 7878688.html (accessed November 27 $\left.7^{\text {th }}, 2017\right)$.

Melo-Martín, I.D. 2014. The ethics of anonymous gamete donation: is there a right to know one's genetic origins? Hastings Center Report, 44(2): 28-35.

Mills, C. 2003. The child's right to an open future? Journal of Social Philosophy, 34(4): 499-509.

Nelson, J.L., 1992. Genetic narratives: biology, stories, and the definition of the family. Health Matrix, 2: 71-83.

Ravitsky V. 2010. "Knowing Where You Come From": The Rights of Donor-Conceived Individuals and the Meaning of Genetic Relatedness. Minnesota Journal of Law, Science \& Technology, 11(2): 655-8

Ravitsky, V. 2012. Conceived and Deceived: The medical interests of donor-conceived individuals. Hastings Center Report, 42(1): 17-22.

Ravitsky, V. 2014. Autonomous choice and the right to know one's genetic origins. Hastings Center Report, 44(2): 36-37.

Rawls, J. 2009. A theory of justice: Revised edition. Cambridge, MA: Harvard University Press.

Savulescu, J., \& Kahane, G. 2009. The moral obligation to create children with the best chance of the best life. Bioethics, 23(5): 274-290.

Scheib, J.E., Riordan, M. and Rubin, S. 2003. Choosing identity-release sperm donors: the parents' perspective 13-18 years later. Human Reproduction, 18(5): 1115-1127.

Scheib, J.E. and Cushing, R.A. 2007. Open-identity donor insemination in the United States: is it on the rise? Fertility and sterility, 88(1): 231-232.

Schuman, O. Forthcoming. The Ethical Justification for Banning Gamete Donor Anonymity. Dissertation.

Schuman, O. Unpublished. Does Donor Conception Violate Dignity? 
Segal, D. 2004. Crunk in the Trunk, This American Life. https://www.thisamericanlife.org/radioarchives/episode/279/auto-show?act=1

(accessed November 23 ${ }^{\text {rd }}, 2017$ )

Vanfraussen, K., Ponjaert-Kristoffersen, I. and Brewaeys, A., 2003. Why do children want to know more about the donor? The experience of youngsters raised in lesbian families. Journal of Psychosomatic Obstetrics \& Gynecology, 24(1): 31-38.

Velleman, J.D., (2005). Family history. Philosophical Papers, 34(3): 357-378.

Velleman, J.D., (2008a). The Gift of Life. Philosophy \& Public Affairs, 36(3): 245-266.

Velleman, J. D. (2008b). III. Love and Nonexistence. Philosophy \& Public Affairs, 36(3), 266288.

Weinberg, Rivka, (2016). The risk of a lifetime: how, when, and why procreation may be permissible. Oxford, England: Oxford University Press.

Witt, C. (2005). Family Resemblances: Adoption, Personal Identity, and Genetic Essentialism. In Adoption Matters: Philosophical and Feminist Essays (pp. 265-290), S. Haslanger and C. Witt (eds). Ithaca, NY: Cornell University Press.

Witt, C, 2014. A Critique of the Bionormative Concept of the Family. In Family-making: Contemporary ethical challenges (pp. 49-63) F. Baylis and C. McLeod (eds.). Oxford, England: Oxford University Press.

Wolf, S. 2010. Meaning in life and why it matters. Princeton, NJ: Princeton University Press. 